\title{
Analysis of the Inner Relationship Between Rural Revitalization Strategy and Cultivation of New Professional Peasant
}

\author{
Jing Jin \\ College of Economics and Management \\ Yunnan Agricultural University \\ Kunming, China 650201
}

\author{
Yankun Peng* \\ College of Foreign Languages and Culture \\ Chengdu University \\ Chengdu, China 610106 \\ *Corresponding Author
}

\begin{abstract}
China's agriculture is facing a transition from tradition to modernity. The rural youth labor force continues to shift to urban areas. In the future, the question of "who will plant the land" and "how the land will be planted" will become more prominent. The key to solving this problem is to increase the cultivation of new professional peasants, improve the quality of agricultural employees and accelerate agricultural modernization. The rural revitalization strategy is not only one of the important measures taken to build a welloff society and to build a socialist modern country in an allround way, but also a major decision-making and arrangement in response to the expectations of the peasants for happy life in the future. The key to realization of the rural revitalization strategy is the revitalization of talents. By analyzing the intrinsic relationship between the cultivation of new professional peasants and the rural revitalization strategy, it will help to strengthen the important role of new professional peasants training in rural revitalization.
\end{abstract}

Keywords-rural revitalization; new professional peasants; intrinsic relationship

\section{INTRODUCTION}

Implementing the rural revitalization strategy is not only one of the important measures taken to build a well-off society and to build a socialist modern country in an allround way, but also a major decision-making and deployment in response to the expectations of the peasants for happy life in the future.

The rural revitalization strategy puts forward the general requirements of "prosperous industry, ecological livability, rural civilization, effective governance, and affluent life", which not only sets new standards for economic and ecological construction in agriculture and rural areas but also puts forward higher requirements for the cultivation of new professional peasants in terms of culture, society, and politics and so on.

The revitalization of talents is the key of the realization of the rural revitalization strategy. The new professional peasants are not only the leader in the development of the future agricultural industry, but also undertake the unshirkable responsibility and obligation for the rural revitalization. The new professional peasants should be not only agricultural talents who understand agricultural commerce, management and technology, but also demonstrators of rural ecological civilization construction with social responsibility and those who are responsible for village self-government management.

Since 2012, new professional peasants' cultivation projects have been implemented in all provinces, municipalities and autonomous regions across the country, and have made significant progress by increasing the implementation organizations, innovating mechanisms, institutional systems and sounding systems [1].At the end of 2017, the cultivation of new professional peasants in the country has become the highlight of agricultural and rural economic development and the revitalization of rural talents. The overall scale has exceeded 15 million [2].

China's agriculture is facing a transition from tradition to modernity. The rural youth labor force continues to shift to urban areas. In the future, the question of "who will plant the land" and "how the land will be planted" will become more prominent. The key to solving this problem is to increase the cultivation of new professional peasants, improve the quality of agricultural employees and accelerate agricultural modernization.

By analyzing the internal relationship between the cultivation of new professional peasants and the rural revitalization strategy, this paper explains why the cultivating of new professional peasants is contributable to the implementation of the rural revitalization strategy, and explores how to innovate and improve the institutional mechanisms of cultivating new professional peasants to help the development of rural revitalization strategic.

\section{The Definition of New Professional PEASANTS UNDER THE NEW SITUATION}

Many scholars have different interpretations for the concept of new professional peasants. Zhu Qizhen and Wen Jingchao (2012) believe that the new professional peasants are the main players in the market, and their income is higher 
than that of ordinary peasants. As a lifelong career, they are more stable and have a high sense of social responsibility and modern consciousness [3]. Zeng Yichun (2102) believes that the concept of new professional peasants should have the characteristics of the times, stage and region, meanwhile, it is developing and changing. In a word, new professional peasants refer to the person whose main career is agricultural production, management or service and source of livelihood is agricultural income. Besides, they have certain production and management skills of modern agricultural, and have high scientific and cultural qualities [4]. Jiao Fuli et al. (2014) believe that new professional peasants are agricultural professionals whose main careers are agricultural production, management, operation or service. Meanwhile, they have scientific and cultural qualities, master modern agricultural production skills, and have certain management capabilities [5].

In 2017, Xi Jinping gave a new expression to the new professional peasants, saying that "the economic and social development in rural areas, in the final analysis, the key lies in people. It is necessary to make wealthy peasants, raise peasants, support peasants, and make agricultural operations profitable, so that agriculture can become a headed industry and let peasants become decent jobs [6]. It is pointed out that the economic and social development of rural area requires the cultivation of more new professional peasants who love agriculture, understand technology and operate well.

By summarizing the expressions of new professional peasants given by scholars and the government, the connotation of the new professional peasants is of an era and has different meanings at different development stages. Under the new situation, the new professional peasants have the following features: loving the countryside, cherishing the landscape of the countryside, and understanding how to protect the rural ecology. They master the modern agricultural production technology and the modern agricultural marketing skill. They have deep emotions to peasants, and hope to bring ordinary peasants together to get rich. Under the new situation, the new professional peasants cover all the employees who take the rural revitalization strategy as the target and new agricultural operation as core, serve the modern agricultural management, production, circulation and service. They are pioneers that can be responsible for the prosperity of the industry, the building of ecologically livable environment, developing rural civilization, and the democratic governance of rural area. The new professional peasants include not only operators, science and technology management personnel, and agricultural workers who directly serve the new business entities, but also agricultural social service providers who indirectly serve the new business entities, and agricultural product marketers who use modern information technology to promote agricultural products and so on.

The concept of "professional peasant" means that "peasant" is a freely chosen profession and no longer a given identity. From the perspective of economic development, the cultivation of new professional peasants is conducive to the optimal allocation of broader labor resources in the context of shrinking demographic dividends and continuous decline in rural labor resource supply. It is beneficial to the sustainable development of agriculture and rural areas, and is beneficial to the development of urban and rural integration. [6] From the perspective of social development, a new type of social development is proposed. The cultivation of professional peasants is in line with the concept of "innovation, coordination, green, openness, sharing", respecting people's individuality and choice, and stimulating the enthusiasm and creativity of workers [7].

\section{THE INTERNAL RELATIONSHIP BETWEEN NEW PROFESSIONAL PEASANTS, NEW AGRICULTURAL MANAGEMENT ENTITIES AND RURAL REVITALIZATION STRATEGIES}

The relationship between rural revitalization and strategic new professional peasants and new agricultural management entities is inseparable. Rural revitalization is the strategic goal of the cultivation of new professional peasants and new agricultural management entities. The new professional peasants are the main practitioners of rural revitalization The new agricultural management entities are important rural economic organizations that carry rural revitalization. New professional peasants and new agricultural management entities is complementary.

\section{A. The Close Relationship Between New Professional Peasants and New Agricultural Management Entities}

New professional peasants are inseparable from the new agricultural business entities. The new agricultural business entities are an important organizational form for realizing the scale, intensification, specialization, and organization and socialization production of modern agriculture in China. New professional peasants serve the main body of new agricultural operations, which are the most important intellectual, technical and labor resources of such production organizations. "Production and management" professional peasants are the managers, operators and decision makers of the new agricultural management entities. "Professional Skills" professional peasants are professional technicians, technical supporter and servicer of new agricultural management entities. "Social service" professional peasants are mechanized scale servicers for the homogeneous labor in various agricultural productions of new agricultural management entities, and they are all indispensable components of new agricultural management entities.

New professional peasants and new agricultural management entities are the two breakthrough points for China to develop modern agriculture. The new agricultural management entities are the carrier of new professional peasants. If there is no new type of agricultural management entities with specialization, high efficiency, low cost and competition, the new professional peasants would lose the soil for survival and development and become a wood without roots. The new professional peasant is the intellectual resource and power of the new agricultural management entities, and is the creator, manager, operator and producer of the new agricultural management entities. The new agricultural management entities will lose the driving force for development if there is no new professional 
peasant with "good management, know technology, and love agriculture" [7]. There will be no high efficient, safe modern agriculture and new agricultural management entities with market competitiveness if there is no new professional peasant with high-quality, technically-savvy, specialization and hard-working. The cultivation and development of new agricultural management entities and the cultivation of new professional peasants are "you have me, I have you", complemented each other and inseparable.

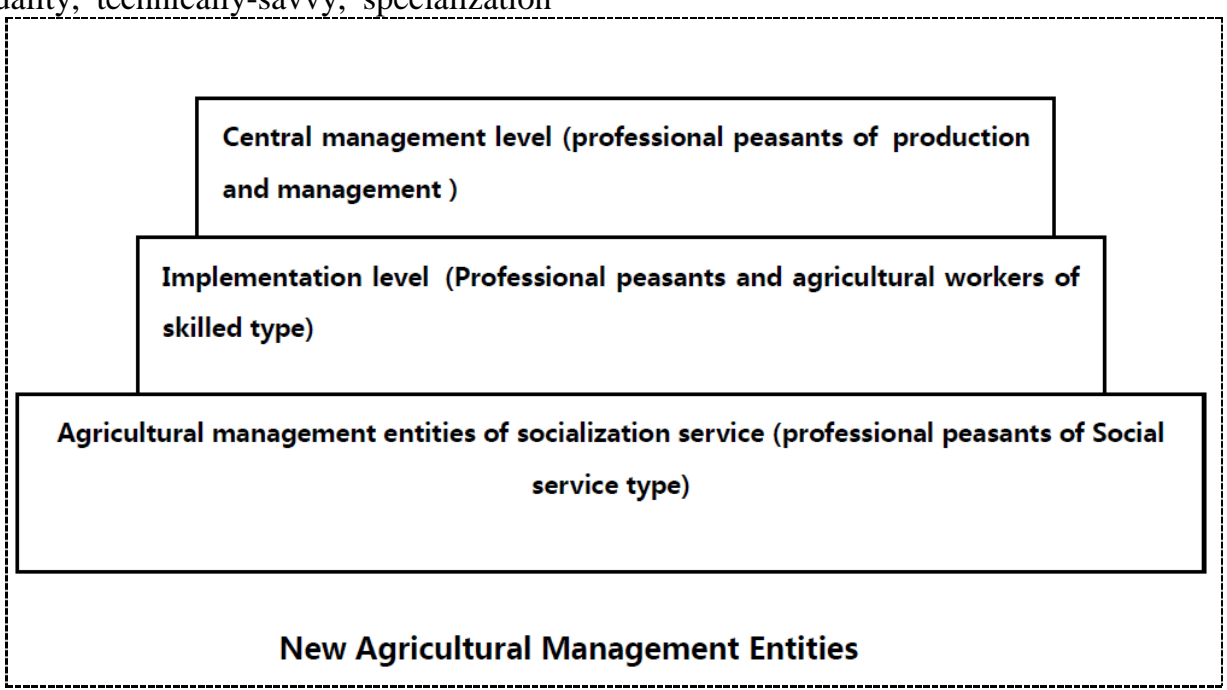

Fig. 1. Relationship between new agricultural management entities and new professional peasants

\section{B. New Professional Peasants - the Main Practitioners of Rural Revitalization Strategy Practice}

New professional peasants should be important participants and implementers of the rural revitalization strategy, which is determined by the characteristics of the new professional peasants. First of all, the new professional peasants are the elites of the rural areas. Most of the new professional peasants have certain knowledge, technology and good management skill. They are flexible, more thoughtful, can accept new things more quickly, and can better understand the meaning, implementation path and practical methods of rural strategy. Secondly, the new professional peasants have long been rooted in the rural areas in the process of agricultural management. They are either peasants or new peasants who live with the peasants, and can better understand the peasants' ideas and needs. Therefore, in the process of implementing the rural revitalization strategy, the true wishes and needs of the villagers can be better reflected and expressed. In addition, the new professional peasants often contact with the outside world during their operation or training, and their horizons are relatively broad. They are good at introducing the advanced technologies and concepts in the society to the countryside in the implementation of the rural revitalization strategy. Therefore, it is necessary to fully mobilize the enthusiasm of new peasants so that they can actively participate in all aspects of rural revitalization.

New professional peasants should be direct implementers of industrial prosperity. Based on modern agriculture, "Prosperity of the industry" is market and green ecology oriented. It focuses on developing and strengthening "highefficiency green planting industry, agricultural product processing and circulation industry, leisure agriculture and rural tourism, rural service industry and local characteristic industry" [7]. The cultivation and growth of the industry cannot be separated from the leaders who understand the market and the good management. The development of the industry cannot be separated from the support of modern agricultural technology. The low cost of the industry cannot be separated from the professional service team. The production of the industry cannot be separated from the welltrained agricultural industrial workers.

New professional peasants should be the real creators of ecological livability. To achieve rural ecological livability, not only should there be perfect public facilities, clean and tidy living environment, but also fresh air, beautiful and healthy natural environment. Therefore, in addition to the renovation of rural housing, rural rain and sewage diversion, and garbage disposal, the rectification of villages and villages is inseparable from the protection and reconstruction of beautiful and healthy ecological environment by modern agriculture. By improving the ecological awareness of new professional peasants, respecting nature, adapting to nature, and protecting nature, we will build an agricultural modernization in which people and nature live in harmony [8]. The use of green and ecological farming techniques and the reducing use of chemical fertilizers and pesticides will provide adequate and safe agricultural products, maintain the cleanliness of the rural air and create quiet and beautiful rural scenery. The new professional peasants should be the main practitioners of the rural civilization. The essence and core of rural civilization is knowledge, civilization and modernization [9]. The operators and managers of the new professional peasants generally receive formal education, have a certain level of knowledge and culture, are the leaders of the agricultural industry, and have certain influence in the countryside. The behaviors such as words and demeanor, social interaction and family relations are most likely to be emulated by the villagers and become the vane of the village. 
The new professional peasants should be fulfilled in the civilized rural style, good family style, and simple folk customs, so that they become practitioners and advocates of the rural civilization.

New professional peasants should be important participants in community governance. Peasants' participation in rural community governance is an effective way to promote grassroots democracy and promote rural community governance. Peasants still have many problems in the process of participating in grassroots governance: First, the types of participants are not wide, and there is an imbalance in the participating groups; secondly, the individual's participation power is limited, and its own demands are not reflected or guaranteed in the collective policy, and the enthusiasm is not high; Furthermore, due to the slow or unsound development of rural social organizations, the channels for participation through social organizations are very limited. Finally, influenced by feudal ethics and self-sufficient small-scale peasant economy in the past, participants formed a strong sense of obedience and collective identity, and they are only in a passive obedience position. Therefore, the scope and level of participation were low [10]. The new professional peasant is the main bearer of the operation of the new agricultural operation entities. The new professional peasants participate in the rural community governance, which not only represents the new professional peasant themselves, but also represents the participants or related parties of the new agricultural management entities to a certain extent.

\section{The New Agricultural Management Entities - Carrier of the Revitalization Strategy Implementation of the Rural Area}

The cultivation of new agricultural management entities is the key to achieve industrial prosperity. Industrial prosperity should start with the system and mechanism of innovative agricultural management and operation, and accelerate the transformation of agricultural management and operation mode. The cultivation of new agricultural management entities is the key to changing the scale of traditional agricultural management, extensive form, labor aging, low degree of organization, and inadequate service system, achieving the goal of industrial intensification, specialization, organization, and socialization of industrial prosperity [11]. Cultivating new agricultural management entities is not only the need for industrial prosperity, but also the requirement for accelerating the development of modern agriculture in China.

The new agricultural management entities are an important main body to maintain the livability of rural ecology. The new agricultural management entities is the main body of production and management of modern agriculture, and the village is the main place for its agricultural production and management. Its production and operation methods will have a huge impact on the rural ecology. In the process of agricultural production development, we will pay attention to protect the original vegetation of the mountain forest, not over-exploiting, maintaining the local ecological diversity, and retaining the green mountains and clean waters. In the process of agricultural production, use appropriate amount of safe fertilizers and pesticides should be used to produce ecological products, maintaining the ecological security of the village.

After the harvest of agricultural products, the crop stubs are treated as ecologically as possible into the ecological cycle. The new agricultural management entity can maintain the beautiful, ecological and livable rural environment through ecological production methods.

\section{CONCLUSION}

The rural revitalization strategy is the strategic goal of cultivating new professional peasants and new agricultural management entities. Cultivating new professional $\mathrm{s}$ and new agricultural management entities provide services and support for rural revitalization. In the production, operation and development of new professional peasants, the development concept of rural revitalization could be found everywhere. The cultivation of new professional peasants must be closely linked to the cultivation of new agricultural management entities at the strategic level of rural revitalization. Clearly understanding the intrinsic relationship between rural revitalization and the cultivation of new professional peasants mean much to realize the "industry revitalization, talent revitalization, cultural revitalization, ecological revitalization and organizational revitalization" of the rural areas".

\section{REFERENCES}

[1] Science and Technology and Education Ministry of Agriculture Department. "13th Five-Year Plan" for the cultivation and development of national new professional peasants. Agriculture Development. January 2017.

[2] Wang Hao. This year the central government will continue to arrange subsidy funds of 2 billion yuan. People's Daily Online - People's Daily. May 20, 2018.

[3] Zhu Qizhen, Wen Jingchao. On New Professional Peasants and their Cultivation. Agricultural Engineering. 2012(3):1-4

[4] Zeng Yichun. Perfecting the Institutional Design and Strengthening the Practice Exploration - Some Thoughts on Cultivating New Professional Peasants. Peasant Daily. June 13, 2012

[5] Jiao Fuli, Zhang Guoxiang,etc. Investigation and Thinking on the Training Mode of New Professional Peasants [J]. Modern Rural Science and Technology, 2014(3):75-78.

[6] Zhang Fuwei, Wei Lijie. Xi Jinping: Jiuzi defines a new type of professional peasant. CCTV Net, April 13, 2017

[7] Zhang Fuwei, Wei Lijie. Love agriculture, understand technology, good management, general secretary, nine words, defines new professional peasants [J]. CCTV Net, 2017.4.8.

[8] "Han Changfu, Minister of Agriculture: Industry boom is the first place in rural revitalization", The Paper, December 30, 2017.

[9] Wu Hongliang. Rural Civilization Helps Rural Revitalization [J] Zhejiang Online, March 29, 2018 